

BNL-73457-2005-CP

\title{
Upgrade of RHIC Vacuum Systems For High Luminosity Operation
}

\author{
H.C. Hseuh, M. Mapes, L.A. Smart, R. Todd, D. Weiss \\ Presented at the Particle Accelerator Conference(PAC'05) \\ Knoxville, Tennessee \\ May 16-20, 2005
}

\author{
Collider-Accelerator Department \\ Brookhaven National Laboratory \\ P.O. Box 5000 \\ Wpton, NY 11973-5000 \\ www.bnl.gov \\ Managed by \\ Brookhaven Science Associates, LLC \\ for the United States Department of Energy under \\ Contract No. DE-AC02-98CH10886
}

This is a preprintof a paper intended for publication in a journal or proceedings. Since changes may be made before publication, this preprint is madeavailablewith the understanding that it will not be cited or reproduced without the permission of the author. 


\section{DISCLAIMER}

This report was prepared as an account of work sponsored by an agency of the United States Government. Neither the United States Government nor any agency thereof, nor any of their employees, nor any of their contractors, subcontractors, or their employees, makes any warranty, express or implied, or assumes any legal liability or responsibility for the accuracy, completeness, or any third party's use or the results of such use of any information, apparatus, product, or process disclosed, or represents that its use would not infringe privately owned rights. Reference herein to any specific commercial product, process, or service by trade name, trademark, manufacturer, or otherwise, does not necessarily constitute or imply its endorsement, recommendation, or favoring by the United States Government or any agency thereof or its contractors or subcontractors. The views and opinions of authors expressed herein do not necessarily state or reflect those of the United States Government or any agency thereof.

FOR UNCLASSIFIED, UNLIMITED STI PRODUCTS

Available electronically at:

OSTI:

http://www.osti.gov/bridge

Available for a processing fee to U.S. Department of Energy and its contractors, in paper from:

US. Department of Energy

Office of Scientific and Technical Information

P.O. Box 62

Oak Ridge, TN 37831

Phone: (865) 576-8401

Facsimile: (865) 576-5728

E-mail: reports@adonis.osti.gov

National Technical Information Service (NTIS):

Available for sale to the public from:

U.S. Department of Commerce

National Technical Information Service

5285 Port Royal Road

Springfield, VA 22131

Phone: (800) 553-6847

Facsimile: (703) 605-6900

Online ordering: http://www.ntis.gov/ordering.htm

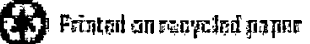




\title{
UPGRADE OF RHIC VACUUM SYSTEMS FOR HIGH LUMINOSITY OPERATION"
}

\author{
H.C. Hseuh ${ }^{\dagger}$, M. Mapes, L.A. Smart, R. Todd and D. Weiss, BNL, Upton, $N Y$ 11973, USA
}

\begin{abstract}
With increasing ion beam intensity during recent RHIC operations, rapid pressure rises of several decades were observed at most warm sections and at a few cold sections. The pressure rises are associated with electron multi-pacting, electron stimulated desorption and beam ion induced desorption; and have been one of the major intensity and luminosity limiting factors for RHIC. Improvement of the warm sections has been carried out in the last few years. Extensive in-situ bakes, additional UHV pumping and anti-grazing ridges have been implemented. Several hundred meters of NEG coated beam pipes have been installed and activated. Vacuum monitoring and logging were enhanced. Preventive measures, such as pumping before cool down to reduce monolayer condensates, were also taken to suppress the pressure rises in the cold sections. The effectiveness of these measures in reducing the pressure rises during machine studies and during physics runs are discussed and summarized.
\end{abstract}

\section{INTRODUCTION}

RHIC has a circumference of $3.8 \mathrm{~km}$ and comprises two interweaving rings (named yellow ring and blue ring) that intersect with each other at six locations. The total length of warm sections is $\sim 1.4 \mathrm{~km}$, consisting of 24 insertion regions (single beam) at both ends of the long arcs, 12 final-focusing beam-merging regions between $\mathrm{DO}$ and $\mathrm{DX}$ (both beams) and six interaction regions $(\mathbb{F})$, as shown schematically in Fig. 1. The design vacuum of the warm sections is $<5 \times 10^{-10}$ Torr. The beam-gas lifetime, dominated by nuclear scattering with cross sections of $\sim 10^{-24} \mathrm{~cm}^{2}$ for $\mathrm{Au}$, is -400 hours at this vacuum level, much longer than the ten-hour intra-beam scattering lifetime [1]. Backgrounds to the detectors, due to beamgas events in warm sections bracketing the experimental detectors set the RHIC beam vacuum requirements [2]

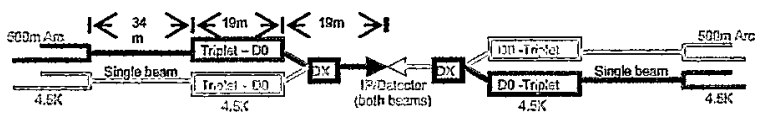

Figure 1. RHIC warm sections bracketing the interaction points showing the incoming and outgoing single beam lines and the common lines at IP and DX-DO.

The warm sections are pumped by ion pumps (IP) and titanium sublimation pumps (TSP), and monitored with cold cathode gauges (CCG) at intervals averaging $14 \mathrm{~m}$. Due to the small linear conductance of the beam tubes, the

\footnotetext{
*Workperformed under Contract No. DE-AC02-98CH1-886 with the auspices of the US Department of Energy thseuh@bnl.gov
}

effective pumping speeds are in the order of tens $1 / \mathrm{s} . \mathrm{m}$ for $\mathrm{H}_{2}$ and a few 1/s.m for CO. The average pressures of the warm sections without beam have reached below the design vacuum level, owing to the gradual bakeouts of these sections over the last few years.

Rapid pressure rises of several decades occurred during the high-intensity runs in the last few years and have caused high detector backgrounds. The pressure rise was especially prominent during $108 \mathrm{~ns}$ bunch-spacing injection. Extensive bakeouts of the warm sections and other improvement were carried out to reduce the pressure rise at high beam intensity. Further improvement of the vacuum systems planned for the 2005 shut down is also described.

\section{VACUUM IMPROVEMENT}

\section{Pressure Rise vs. In-Situ Bake}

Two types of pressure rise have been observed in the last few years. The first type is the pressure rise at injection, occurred when beam intensity was above certain threshold $\left(I_{t \mathfrak{t a}}\right) . I_{\text {th }}$ is very sensitive to bunch intensity and spacing, and electron cloud is responsible for this type of pressure rise [3]. It has limited the $\mathrm{Au}$ intensity for 55-bunch injection, and prevented the 110bunch mode operation. The second type of pressure rise occurred at the transition and rebucketing [4], and is proportional to the total beam intensity, but not sensitive to the bunch intensity and spacing. This type of pressure rise has caused high detector background and hampers further luminosity improvement.

Many warm sections have been in-situ baked over the last few years to reduce secondary electron yield (SEY) and molecular desorption yield, the resulted pressure rise, and to increase $\boldsymbol{I}_{\text {th }}$. The loosely bound surface contaminants have a much higher SEY and can be removed through in-situ bake. The electron stimulated desorption (ESD) and the beam ion induced desorption are also lowered with in-situ bake. The intensity thresholds of the first type pressure rise can be obtained by analyzing the pressure rise patterns under various running conditions [3], especially during high intensity injections. The effectiveness of the bakeouts and other improvements to increase $I_{\text {fh }}$ is summarized in Table $I$, where the pressure rise $I_{t h}$ at one single beam region (BO1 1) and at one interaction region (IR.12) are compared with various vacuum conditions over the last few runs. The threshold beam intensities $\mathrm{I}_{\text {th }}$ of various species are converted to Au charge equivalent, for example the total 
$\mathrm{Cu}$ ions were divided by $2.7\left(=Z_{\mathrm{Au}} / \mathrm{Z}_{\mathrm{Cu}}\right)$ and that of proton and deuteron by 79 to give the $\mathrm{Au}$ charge equivalent in unit of $10^{9} \mathrm{Au}$ ions. For the initiation of pressure rise at injection, $I_{\text {th }}$ was about a factor of two higher after bake (e.g. 2001 and 2002 vs. 2003). $\mathbf{I}_{\text {th }}$ has increased further with the addition of NEG coated beam pipes at these sections. The equivalent $\mathrm{I}_{\text {th }}$ for $\mathrm{p}, \mathrm{d}$ and $\mathrm{Cu}$ are higher than that of $\mathrm{Au}$, even after factoring in the total charges.

Table 1. $\mathrm{I}_{\mathrm{th}}$ expressed at $10^{+9} \mathrm{Au}$ charge equivalent for different species and running modes at IR12 (IP) and B011 (Single). NEG coated beam pipes were installed and activated in these re 'om for 2004 run (IP onl ) and 2005 run.

\begin{tabular}{|l|l|l|l|}
\hline \multicolumn{2}{l}{} & \multicolumn{2}{l|}{2002 -not baked } \\
\hline-110 & 114 & $\sim$ & 2002 -not baked \\
\hline$p-110$ & 126 & 76 & 2005 - NEG \\
\hline$d-55$ & $>150$ & $>89$ & 2003 - baked \\
\hline$d-110$ & & 89 & 2003 - baked \\
\hline $\mathrm{Cu}-55$ & $>92$ & $>92$ & 2005 - NEG \\
\hline $\mathrm{Cu}-110$ & $>55$ & $\sim 55$ & 2005 - NEG \\
\hline $\mathrm{Au}-55$ & $\sim 70$ & 20 & 2001 - not baked \\
\hline $\mathrm{Au}-110$ & $\sim 60$ & 10 & 2001 - not baked \\
\hline $\mathrm{Au}-55$ & $>120$ & 45 & 2003 - baked \\
\hline $\mathrm{Au}-110$ & & 35 & 2003 - baked \\
\hline $\mathrm{Au}-55$ & $>100$ & $>50$ & 2004 - NEG \\
\hline
\end{tabular}

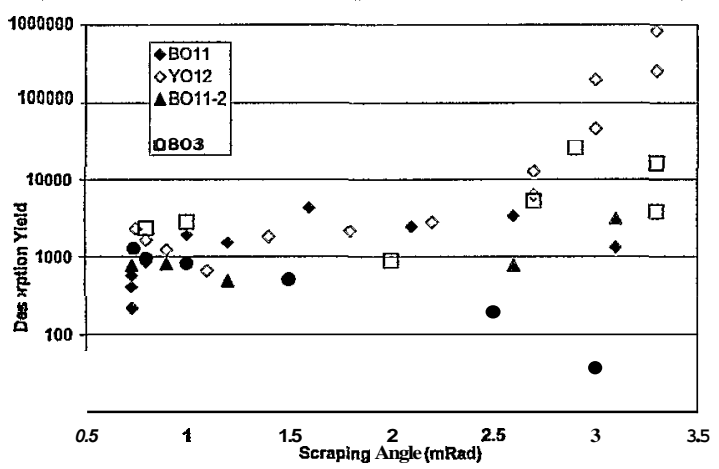

Figure 2. The $\mathrm{Cu}$ beam ion induced desorption yields from vacuum chamber wall vs. incident angles for stainless beam pipes (open markers) and NEG coated surface (filled markers) at single beam insertion regions. The effective desorption yields of NEG coated pipes are several times lower than the ones without coating.

\section{NEG Coating of Warm Beam Pipes}

To increase the effective pumping speed, linearly distributed pumps in the form of NEG coated beam pipes [5] have been installed in RHIC warm sections. The NEG coating will provide effective pumping speed of $>10^{2}$ $1 / s . m$ and will reduce the SEY, and the electron and ion desorption rates. The NEG coating of the standard $12 \mathrm{~cm}$ diameter insetion beam pipes was contracted to SAES Getters, Inc. with license from CERN. Up to this date, approximately $250 \mathrm{~m}$ of NEG coated pipes have been installed and activated. The pressure rise threshold of the NEG coated sections, as shown in Table 1, is found to be higher than un-coated sections (for example, p-110 in
2005 vs p-110 in 2003 for the single beam section). The magnitude of pressure rise at warm sections with NEG coated beam pipes is also lower than that of un-coated sections [4]. However, the magnitude of the pressure reduction is not as dramatic as one would expect based on pumping speed along. The beam ion induced desorptions of the NEG coated and un-coated sections have been studied using $\mathrm{Cu}$ beam at $10 \mathrm{GeV} / \mu$ and the result is shown in Fig. 2. The un-coated section has effective desorption coefficients about one decade higher than the coated sections [6]. Additional 250m NEG coated beam pipes will be installed in the upcoming shutdown.

\section{Cold Bore Pressure Rise}

Pressure rise of a few decades, as shown in Fig. 3, has been observed in some cold sections during machine studies with $108 \mathrm{~ns}$ bunch spacing. This was measured by cold cathode gauges at room temperature connected to the cold bore through a small conduit with conductance of ${ }^{-1} 1$ $1 / \mathrm{s}$ for hydrogen. Assuming balanced gas flow to and from the cold bore and considering thermal transpiration, the real gas density in the cold bore is about one decade higher than the gauges indicated. This cold bore pressure rise was caused by electron cloud and ESD. To reduce ESD for high luminosity operation, the amount of cryocondensed gas has to be reduced to less than one monolayer. Without active pumping, the cold sections would usually drift to $10^{-1}$ Torr level during the annual summer warm up, equivalent to -10 monolayers of condensed gas after cool down. Some of the 40 cold bore sections had been pumped out to below $10^{-3}$ Torr before cool down, to evaluate its effect on the cold bore pressure rise. Rouging pumps and small ion pumps will be installed to pump and maintain the cold bore at high vacuum levels after warm up. Additional hydrogen pumping will also be implemented in the future at warmcold transition to reduce hydrogen migration from some warm sections to near by cold sections.
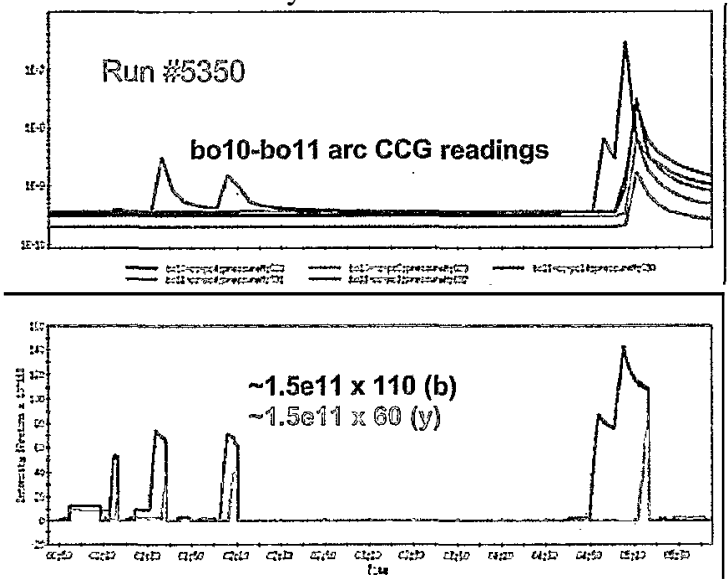

Fig. 3. Pressure rises (top) in the arc cold bore during 110-bunchproton (bottom) injections. The pressures were monitored with cold cathode gauges at room temperature connected to cold bore through a small conduit, resulted in readings a decade lower than the actual gas density in the cold bore. 


\section{VacuumMonitoring}

The monitoring and control of RHIC vacuum devices is through the use of RS485 serial communication. Up to 32 like devices are connected to a common PLC coprocessor port. Due to the integral processing time of the co-processors, the digital vacuum readings are updated $\sim$ every 8 seconds for vacuum gauges, and up to 30 seconds for multi-parameter devices like residual gas analyzers and turbopump stations. To monitor and correlate the pressure rise with the beam intensity and other machine parameters, faster data logging was implemented. The analog output signals of selected CCGs from both warm and cold sections were fed into MADC modules, digitized and logged at rates up to $10 \mathrm{~Hz}$. The enhanced cata logging capability allows accurate comparison and correlation of the pressure rise with the signals from beam current monitors, electron detectors, beam loss monitors and other diagnostics.

\section{FUTURE IMPROVEMENT}

To meet the luminosity goals in RHIC for year 2006 and beyond, the total beam intensity has to be increased by a factor of two or more, through increased bunch intensity, number of bunches or both. The expected pressure rise during injection and transition will be excessive based on observation from the past runs. The following remedies are being planned to further reduce the pressure rise.

\section{In-Situ Bake of Diagnostic Devices}

The major goal in the last few years was to lower the pressure rise at the incoming insertion sections and at the common beam lines around the detectors, thus reduce the beam-gas background to the major experiment detectors. However, during a few high intensity stores, excessive pressure rise was observed at the outgoing lines where most diagnostic equipments were located. This high pressure has caused large amount of beam scattering and beam loss in the long arcs. Therefore individual devices, such as polarimeters and IPM, in the outgoing sections will be evaluated and in-situ baked to the maximum allowable temperature to reduce the static and dynamic pressure. Non-conventional bakeout methods will be developed for some of these devices.

\section{Vacuum Upgrades of Interaction Regions}

The beam intensity limits at RHIC are mainly at a few interaction regions, where the pressure rise has been the highest, due to tho doubling of the number of bunches. Upgrade of the $\mathbb{R}$ vacuum, however, is most difficult since the beam pipes are integral part of the experimental detectors which prevent the addition of conventional pumps or thorough in-situ baking. Furthermore, the IR beam pipes are made of beryllium and aluminium for their transparency to energetic particles. Both beryllium and aluminum have high SEY as compared with stainless surface. The upgrade path for each IR will be different depending on the exact nature of the detectors and the beam pipes. In general, the plan is to coat the $7 \mathrm{~cm}$ diameter IR beam pipes with NEG and activate it if possible. If fully activated, the coating should have low SEY, low ESD and high linear pumping speed. Partially activated NEG surface should also provide the advantage of lower SEY. The vendor for the NEG coating of RHIC $12 \mathrm{~cm}$ insertion stainless beam pipes is not interested to coat RHIC beryllium beam pipes, which are up to $8 \mathrm{~m}$ in length, brittle, toxic and very expensive to replace; and may have residual radiation. Development of NEG coatings using an innovative horizontal magnetron cathode [7] has been carried out in the last year. Test pipes of similar dimensions to the IR pipes have been successfully coated using this DC magnetron sputtering technique developed for titanium nitride coating of SNS accumulator ring vacuum chambers [8]. Coating of actual IR beam pipes will start this coming shutdown when the actual beam pipes are removed from the detectors.

\section{SUMMARY}

Improvement of the RHIC vacuum system before 2005 physics runs has produced some positive effect on the beam intensity thresholds for the pressure rise as compared with previous runs. The magnitude of the pressure rise is also lower than that of the previous years. Both thorough in-situ bakeouts and NEG coated beam pipes have offered the most benefits in reducing the pressure rise during high intensity ramps. Further improvement, especially at interaction regions and at cold bore sections, is needed to allow further luminosity development. To that end, the NEG coated beam pipes will be installed at $I R$, and the surface condensates in the cold bore will be reduced to below a monolayer through activepumping after warm up.

\section{ACKNOWLEDGEMENTS}

The authors would like to thank W. Fischer, H. Huang, U. Triso-Ariz and S.Y. Zhang for fruitful discussion and members of Collider-AcceleratorVacuum Group for their relentless effort in improving the RHIC beam vacuum systems.

\section{REFERENCES}

[1] M.J. Rhoades-Brown and M. A. Harrison, RHIC Technical Note \#106, BNL-47070, Dec. 1993.

[2] H.C. Hseuh, et al, Proc. PAC'99, 557 (1999).

[3] W. Fischer, et al, Proc. ECLOUD'04, 'Electron Clouds and Vacuum Pressure Rise in RHIC', Napa, CA (2004).

[4] S.Y. Zhang, et al, 'Beam Induced Pressure Rise in RHIC', these proceedings.

[5] C. Benvenuti, Proc. PAC'01, 602 (2001).

[6] H. Huang, et al, 'Beam Pipe Desorption Rate in RHIC', these proceedings.

[7] D. Weiss, et al, 'Development of NEG Coating for RHIC ExperimentalBeam Tubes', these proceedings.

[8] R. Todd, et al, 'Summary of TiN Coating for SNS Ring Vacuum Chambers', these proceedings. 